\title{
Existe lugar para o signo na história da mídia*?
}

\section{RESUMO}

Existe um ponto de vista já bastante consolidado sobre a compreensão do que se entende por história social da mídia. Trata-se da abordagem que acompanha não apenas a introdução dos meios de comunicação na cultura, como também as alterações provocadas no cenário das relações sociais. Essa é uma história que acompanha o encadeamento das invenções tecnológicas no sentido de sua eficácia. Por isso mesmo, filia o conceito de comunicação à noção de transporte. Não consta dessa abordagem, a interação pela linguagem, colocando em pauta o seguinte questionamento: existe lugar para as mediações semióticas na história social da mídia? Se houver, qual é esse lugar? Após percorrer os estudos históricos sobre a abordagem histórica da mídia, o presente estudo elabora a defesa de uma história das mediações semióticas resultante do desenvolvimento dos códigos culturais que não são invenções da tecnologia industrial, mas das tecnologias do intelecto.

\section{PALAVRAS-CHAVE}

história da mídia

sistemas de signos

códigos culturais

\begin{abstract}
There is a well known tradition refering to the social history of media based on the development of media in culture and in its effects on the social relationship scenary. That is the history focused on the set of technological inventions and its efficiency as means of communication. In the context of this approach there is no place to the study of language interaction. There are so many question we can put here and to consider as the main aim of this essay. The main question is: is there a place to sign in the social history of media? If we answer yes, another question should be considered: which is that place? In fact, the main point of this argumentation concern to the need of understanding not the history of media in general but the history of cultural codes in the process of mediation.
\end{abstract}

\section{KEY WORDS}

history of media

sign systems

cultural codes

\section{Irene Machado \\ USP \\ irenemac@uol.com.br}

Para historiadores da cultura, história da mídia é um campo de investigação destinado ao exame das mudanças no quadro das relações sociais a partir das descobertas e da proliferação de veículos que, direta ou indiretamente, alteraram padrões de convívio, interferindo no modo como as interações sociais são realizadas. Nesse sentido, define-se a história da mídia como uma história social em que figuram, como seus protagonistas os episódios que marcam épocas e consolidam novas formas de relacionamentos sociais. No contexto da civilização ocidental, a história social da mídia consagrou os meios de comunicação de massas e a cadeia de eventos que provocaram a "revolução na comunicação" (Carpenter \& McLuhan, 1980) como o grande evento que inaugura a "era da informação" (Castells, 1999). Esses eventos são sem sombra de dúvidas as grandes invenções tecnológicas da era industrial e informática - o telégrafo, o rádio, o telefone, o computador, as telecomunicações, os sistemas de rede, os cabos, a Internet, a telefonia sem fio (Briggs \& Burke, 2004: 13) - que viabilizaram, e continuam a viabilizar, a transmissão da informação de um modo cada vez mais eficiente e o aprimoramento de competências científicas específicas (Winston, 1998). Essa é uma trajetória diacrônica voltada para as formas pelas quais a mídia conferiu contornos à comunicação, realizada pelos meios tecnológicos industriais e informáticos detentores do poder de definição da história da cultura e do caráter da própria civilização (Marvin, 1988).

Para a história da mídia conduzida pelos inventos tecnológicos industriais e informáticos, os veículos de comunicação em larga escala são peças-chave do andamento civilizacional. De suas transformações dependem tanto as facilidades de transmissão da informação quanto a alteração das formas de sociabilidade. Cria-se um vínculo estreito entre o surgimento de meios e as mudanças nas formas de interação social. Este vínculo é revigorado quando se reafirma a noção de comunicação como transporte eficiente. A prova dessa eficiência está no reconhecimento das mudanças que os meios de comunicação introduzem, de maneira quase automática e imediata, nas relações sociais. Por conseguinte, a grande diretriz da história social da mídia é a noção de transporte que está tanto na noção de meios como transmissores de informação, quanto na trajetória de deslocamento de um meio para outro, ou na reconfiguração do quadro das relações sociais. O critério da eficiência assume-se como algoritmo condicionador das mudanças comportamentais: quanto mais eficiente é o processo de transmissão, mais dinâmicas e mais diversificadas serão as interações entre aqueles que desfrutam das tecnologias da comunicação e da informação.

Se a história social da mídia tomou por tarefa acompa- 
nhar os deslocamentos na era da informação, agora, ela própria, se vê obrigada a dirigir sua atenção para um outro deslocamento: aquele que marca a passagem da "era da informação" para a "era da conexão" (Weinberger, 2003 apud Lemos, 2004), amplamente justificada pelo crescimento das tecnologias móveis que, segundo os estudiosos da chamada "cibercultura", têm modificado não apenas as interações interpessoais como também os modos de convivência nos espaços públicos, em suas formas de "produzir e consumir informação" (Lemos, 2004b; retomado em 2004a, 2005, 2007a e 2007b). Batizada como a "era do controle remoto" (Jacomy, 2004), cujos personagens mais promissores são os censores e a nanotecnologia. Por enquanto, o computador é a grande figura, uma máquina de programa, de controles e de comandos cuja finalidade maior é a produção infalível da eficiência que não mais relaciona, mas sim promove a conexão em escala planetária. Se "relação" remete à noção básica de interação numa mesma esfera, "conexão" pressupõe entrecruzamentos complexos entre distâncias e instâncias diferenciadas. Tal é o poder que se credita tanto ao controle remoto quanto à telefonia móvel.

$\mathrm{Na}$ "era da conexão", a telefonia móvel (entendida como um dispositivo de manipulação de controles e comandos) é pólo de operações para o processamento da informação em mensagens entre homens, máquinas e ambientes. André Lemos (2004) que tem dedicado seus estudos às implicações das inserções tecnológicas no conjunto da vida social, esclarece como a telefonia móvel propiciou a "ampliação de formas de conexões entre homens e homens, máquinas e homens, e máquinas e máquinas motivadas pelo nomadismo tecnológico da cultura contemporânea e pelo desenvolvimento da computação ubíqua (3G, WI-FI), da computação senciente (RFID), bluetooth) e da computação pervasiva, além da continuação natural de processos de emissão generalizada e de trabalho cooperativos da primeira fase dos CC (blogs, fóruns, chats, software livres, peer to peer, etc)". Nesse caso, à telefonia móvel se atribui o poder da onipresença; por isso, ainda segundo Lemos, é o invento que provocou o "nomadismo", o desenvolvimento da computação "ubíqua" e "pervasiva", capaz de garantir a possibilidade de se estar em toda parte ao mesmo tempo: "não é mais o usuário que se desloca até a rede, mas a rede que passa a envolver o usuário", afirma ainda Lemos.

Evidentemente a garantia de tal possibilidade é a computação "senciente" em que computadores são interconectados por meio de sensores (Lemos, 2004, nota 2).

O panorama sucinto apresentado tem como objetivo destacar os veículos que se tornaram as principais agentes da história social da mídia na era da conexão e do controle remoto, cabendo a eles o poder de moldar e orientar a interação e a convivência no espaço público nesse início do século XXI. Para eles se voltam as atenções da história da mídia contemporânea.

A história social da mídia conduzida pelas descober- tas tecnológicas capitaneadas pelos meios eletrônicos é, de fato, uma forma legítima e significativa de situar os eventos comunicacionais e suas transformações na história da cultura. Já foram apresentadas provas mais do que suficientes para isso. Por conseguinte, tanto o debate público quanto o fascínio generalizado pelas inovações tecnológicas cada vez mais envolventes, desempenham um papel importante para se pensar essa história.

Será essa, contudo, a única alternativa para se traçar a história da mídia? Somente às tecnologias industriais é dado o poder de definir formas de convívio? As mudanças no quadro das interações são sempre resultantes de um princípio de causalidade tão comum ao determinismo tecnológico?

A noção de que todo o processo de produção e de circulação de mensagens se articula entre meios e efeitos, embora legítimo, não deixa de ser limitado. Ainda que se reconheça o potencial de transformação dos meios, como historiadores, sociólogos, filósofos e comunicadores (desde Marshall McLuhan) não se cansam de demonstrar, o processo de comunicação mediada por máquinas não é uma operação que provoca reações automáticas e imediatas. Na verdade, a causalidade dessa interpretação esconde uma outra premissa não menos importante: a potencialidade cognitiva das invenções tecnológicas. Este é o tema que realmente nos interessa, ainda que não tão discutido. É ele que nos leva a vislumbrar uma outra história não da mídia e seus veículos, mas das mediações e seus processos interativos.

Para começar, os meios de comunicação não são apenas veículos de transmissão; pelo contrário, são formas de manipulação de códigos culturais, estes sim os reais agentes de mediações interativas e das linguagens da comunicação. Do ponto de vista dos códigos a história da cultura desenrola, não uma trajetória, mas tãosomente expansões. Em vez de veículos, transportes e deslocamentos, temos articulações de sistemas cognitivos culturalmente desenvolvidos. Nesse sentido, os códigos culturais assumem o papel que lhes compete enquanto representações das tecnologias do intelecto que, em vez de um mero determinismo causal, tornam possíveis a concretização de processos cognitivos (Vaz, 2002: 101-121).

Ao questionar a causalidade que consagrou um modo de se contar a história social da mídia, estamos preocupados com uma outra questão: qual é o lugar do signo nessa história? Acaso a linguagem não desenvolve história?

Estamos longe de afirmar que a mudança dos meios corresponde à mudança de paisagem ou que o processo de comunicação é transmissão (transporte) da informação. Se é verdade que as tecnologias da informação produzem comunicação e, portanto, linguagens, não se pode ignorar que não apenas o signo, mas classes de signos e de sistemas de signos sejam instâncias de projeções de conhecimento e daquilo que a abordagem semiótica considera "a mente da cultura" (Lotman, 1990). Para tal 
abordagem semiótica, a história dos meios não se limita à história da mídia tal como foi esboçada anteriormente. Busca, outrossim, acompanhar a circulação de signos e de suas recodificações que demandam desenvolvimentos cognitivos diferenciados. Por conseguinte, trata-se de uma história protagonizada pelas mediações de códigos culturais e de linguagens elaborados pelas gestões semióticas do conhecimento. É uma história que não tem um começo muito preciso mas é sempre possível alcançá-la por alguma de suas articulações essenciais e seguir um caminho. Trataremos aqui da história dos meios em suas mediações, segundo a perspectiva das tecnologias do intelecto desencadeadas por um sistema de signos que permite um largo alcance na história da cultura. Este é o sistema inaugurado pela escrita.

\section{Tecnologias do intelecto}

O homem é um ser curioso que vive investigando tudo o que o cerca: suas origens, a origem do Universo, episódios perdidos no tempo, lugares e vidas de seres que, supostamente, nunca existiram. Com isso, já descobriu muitas coisas e já inventou muitas outras. Dentre as suas grandes invenções, a mais fascinante é aquela que modificou radicalmente sua existência com a invenção de um conjunto singular de signos discretos que lhe permitiu desenvolver a escrita alfabética. "Writing is the single most important sign system ever invented on our planet" - é a frase que abre o memorável estudo do lingüista Florian Coulmas (1989: 3) que será tomada aqui como ponto de partida para se compreender a história dos meios pelo viés das mediações semióticas do conhecimento.

Embora seja uma descoberta relativamente recente, se comparada com a fala e com os milhares de anos de nascimento e morte do homem no planeta, a descoberta da escrita alfabética também se tornou um acontecimento "pervasivo" no desenvolvimento da civilização, ainda segundo Coulmas (1989:4). Isso porque a escrita inaugura e dissemina um modo de existência em que os signos discretos são os grandes mediadores das interações. A possibilidade de transformar sinais gráficos ou símbolos pictóricos em sistemas de escrita converteu-se numa das maiores façanhas da história da humanidade, a ponto de não se poder imaginar o mundo em que vivemos sem escrita. Não pela escrita em si, mas pela cadeia de eventos que ela desencadeou e que ainda está longe de ter chegado a um fim. Basta que pensemos, com Coulmas (1989: 4) num mundo "sem livros, sem jornais, sem impostos, talão de cheques, documentos, anúncios, placas de ruas; sem avisos, receitas médicas; sem escola, sem dicionários, sem enciclopédias, sem manuais de instrução para rádio, carros ou computadores". Um mundo sem ciência, sem indústrias, sem leis, sem religião; sem muitas formas de artes; sem cinema, rádio, televisão, computador; sem tudo aquilo que chamamos tecnologia. A própria civilização urbana se confunde com a escrita; prova disso é que a cidade como forma de organização social não existe nas sociedades "orais". E a escrita foi a primeira forma de organização das transações comerciais. Do campo econômico, a escrita partiu para o campo jurídico. Somente mais tarde atingiu o domínio religioso e literário. Será isso suficiente para justificar a importância da escrita bem como o conceito de tecnologia que nela está pressuposto para o processo de gestão semiótica do conhecimento do qual a nossa civilização não pode prescindir?

Travar contato com a história da escrita alfabética, contudo, é andar por "caminhos que se bifurcam", onde se cruzam e se misturam muitos códigos, muitas línguas, muitas linguagens e muitos sistemas de signos ainda que sua base sejam os signos discretos. Contar a história dessa escrita é como contar uma "história sem fim". Uma história que está sempre começando e permite diferentes ordenamentos, como num jogo. Pode-se dizer que começou com as inscrições em cavernas de povos muito antigos; com os sumérios, os fenícios, os egípcios; com as lendas, os desenhos, as inscrições rupestres; com os pictogramas, os ideogramas; com a transformação do som em palavra; com a expansão da palavra em pinturas, em imagens visuais, sonoras, cinéticas. Cito um exemplo: onde artistas que pintaram as grandes catedrais medievais, góticas, renascentistas, poderiam ter encontrado as cenas da vida divina senão nas palavras das Sagradas Escrituras ${ }^{1}$. Ou seja, a história da escrita é uma narrativa cheia de enigmas, de transformações, de expansões. Confunde-se, muitas vezes, com episódios e fenômenos mágicos, sobretudo quando se pensa que o grande personagem dessa história não é exatamente a palavra, mas a operação combinatória de signos que ela propiciou bem como sua expansão.

Nesse sentido, muito mais importante do que a história da escrita é a história de suas conseqüências para a civilização ${ }^{2}$. Nos limites deste estudo, a mais expressiva conseqüência da invenção da escrita está na exploração de códigos culturais como manifestação das tecnologias do intelecto.

Aprendemos com Marshall McLuhan (1971: 76) que "tecnologia" é um processo de "explicitação" com base em experiências e conhecimentos prévios. Assim, "as tecnologias são modos de traduzir uma espécie de conhecimento para outra". Seguindo essa linha de raciocínio, a fala aparece como a primeira tecnologia criada pelo homem: ao colocar em ação o aparelho fonador, explicitou por meio dos sons vocais, uma experiência sensorial. Nesse caso, os sons articulados tornam-se signos potenciais da comunicação oral.

Do ponto de vista semiótico onde nos colocamos, considerar a fala uma tecnologia é uma forma de situar o impulso inicial de uma cadeia geradora de meios e de linguagens que foram constituindo as diferentes gestões do conhecimento. Trata-se de organizar as descobertas sucessíveis e interdependentes em que uma não deixa de prescindir da outra.

Basta atentar para o seguinte: quando o homem in- 
ventou a escrita ele não deixou de falar; quando inventou o rádio, a televisão, o telefone, não deixou de escrever. Pelo contrário, passou, a falar e a escrever utilizando esses meios e modificando a finalidade inicial de muitos deles.

Conceber "tecnologia" como "explicitação" de formas de conhecimentos é o ponto de partida para conceptualizar o que estamos chamando aqui de "tecnologias do intelecto". Trata-se de considerar processos cognitivos traduzidos em operações semióticas a partir de códigos especialmente criados para gerar relações culturais. Isso equivale a dizer que as tecnologias do intelecto abrangem signos e sistemas de signos gerados pela mente da cultura, conhecimento historicamente configurado. Do ponto de vista das tecnologias do intelecto a história dos meios não está vinculada às invenções dos veículos de comunicação nem tampouco aos efeitos nas relações sociais. A natureza semiótica dessas tecnologias faz com que seu desenvolvimento se manifeste como história de mediações. Essa premissa está amparada nas formulações sobre a dinâmica semiótica da cultura.

Quando se descobre que a combinatória de sinais gráficos permitiu a articulação de palavras em sistema de escrita, chegou-se a uma constatação não menos significativa: para que um sistema fosse considerado "escrita" bastava uma única condição: estar codificado de alguma maneira. A construção de códigos tornou-se mecanismo semiótico elementar da cultura (Lotman e outros, 1981), abrindo caminho para interpretações, conversões, traduções, enfim, para tratamento de informações, percepções e de tudo o que é passível de ser significado. Porque são concebidos no contexto de uma mente da cultura, os códigos culturais são sempre representações sensoriais (não necessariamente humanas). Daí toda informação codificada ser potencialmente geradora de sistemas de escrita.

Deste ponto de vista, o homem aprendeu a escrever não apenas com palavras mas com o corpo, com luz, com sons, com movimentos; volumes, texturas, cores; com notações gráficas especialmente criadas. Com eles projetou sistemas de signos capazes de articular conexões. Tome-se por exemplo aquilo que se entende como registro de luz. A codificação da luz é potencialmente geradora de sistemas de escrita: pintura, música, fotografia, dança, filme; ciência, religião; são só alguns deles. Não apenas cada um desses sistemas se articula por meio de códigos distintos (processos fotoquímicos, impulsos elétricos, notações, linhas e cores) como as combinatórias dos códigos criados entram em interação com disponibilidades de contextos diferenciados produzindo outros tantos sistemas de signos. Quer dizer, aquilo que se denomina amplamente por civilização da imagem envolve níveis diferenciados de codificações e de possibilidades combinatórias - não se restringe aos signos visuais. Quando, por exemplo, o contexto da escrita da imagem é a televisão, a combinatória envolve igualmente a codificação de impulsos elétricos, digitais, que tanto podem se reportar à escrita que se oferece por meio de pontos luminosos, quanto àquela que se oferece como escrita de sons, ainda que o código não seja o mesmo daquele que codificou as ondas magnéticas para a produção da escrita radiofônica. Um sistema se explicita a partir de outro e cumpre uma trajetória distinta em sua expansão. Como se pode ver, por mais que se fale em codificação da informação, a escrita como sistema semiótico revela mediações entre vários códigos culturais - a mais singular manifestação das tecnologias do intelecto.

No âmbito de nosso questionamento, a chamada cultura letrada concentra experiências culturais de muitas mediações. Em primeiro lugar pelo fato de ser ela o berço de descoberta da escrita como um sistema pervasivo, retomando aqui a definição de Coulmas, e não por ter criado o alfabeto. Em segundo, por ter desenvolvido a competência cognitiva da leitura, a real consagração da cultura letrada. Pela leitura o homem desenvolveu habilidades de cruzar sistemas de signos articulados por diferentes códigos culturais que não se limitam ao alfabeto e nem a uma classe de signos. Nesse nível de semiose, os códigos se lêem uns aos outros. Por conseguinte, o surgimento do homem leitor - aquele capaz de reconhecer signos e de construir com eles conhecimentos traduzidos em representações - firma a distinção da escrita como tecnologia do intelecto que não se confunde com um mero veículo.

\section{Mediações da informação codificada e recodificada}

Se a escrita é, de fato, este sistema com tal qualidade de pervasividade, a cultura letrada que fomentou sua expansão, não deixa de sê-lo igualmente, sobretudo quando se pensa nas conseqüências da escrita para constituição histórica da cultura. A condição letrada expandiu o conceito de escrita e de leitura. Com isso, a mediação entre os diferentes sistemas de signos apresenta à abordagem semiótica a possibilidade de entender as tecnologias do intelecto pelo viés da interação dos códigos. Esse ponto de vista traz uma implicação importante para o processo da comunicação mediada. Se, como já foi referido aqui, toda informação é codificada de alguma forma em algum sistema de signos, o processo da comunicação mediada opera tão somente com a informação codificada. O que parece ser uma obviedade, torna-se um complicador quando se descobre que os meios de comunicação operam, na verdade, tão-somente recodificações (Sonesson, 1997). Trata-se de operações que não guardam nenhuma relação com a metáfora do transporte amparada no eixo da codificação-descodificação.

Formulada pela teoria matemática da informação, a metáfora do transporte se acomodou muito bem no campo da lingüística uma vez que a comunicação humana centrada na palavra opera, pelo menos em tese, com um único código (vale lembrar que o lingüista Roman Jakobson (1971) já alertara para os limites da codificação única). Aqui aos participantes da cena interativa se atribui o papel de codificador/descodificador; emissor/re- 
ceptor; produtor/consumidor. Esses papéis criaram o diagrama espacial da comunicação fundado na metáfora do transporte e que serviu de paradigma para a compreensão indistinta de todos os meios. É todo esse edifício conceitual que temos questionado ao reconhecer a recodificação como relação elementar das mediações na cultura.

Os meios de comunicação recodificam a informação codificada ao transformar ondas, energia, luz, átomos, bits ou outras configurações (onde se inclui, até mesmo, o pensamento), em codificação de natureza cultural. Quer dizer, criam-se códigos para a organização das informações dispersas em diferentes manifestações e classes de representações ou simplesmente de signos. As informações ópticas, magnéticas, cinéticas, só se constituem em sistemas semióticos traduzidos culturalmente e suscetíveis de transmutações para constituir linguagens processadas por alguma mediação. Na verdade, é imprescindível compreender que os meios só importam a partir do momento em que recodificam a informação (já codificada) em classes de signos.

Podemos voltar ao exame da registro da luz, como forma de escrita resultante da codificação da informação luminosa, citando um exemplo que ainda hoje desperta polêmica. Quando o artista russo, Kasimir Maliévitch (1878-1935), vislumbrou a possibilidade de representar a luz num quadrado branco sobre um fundo branco, ele recodificou a informação luminosa em termos de linhas e cores numa superfície (tela) plana (bidimensional) e branca. "Luz" é a informação dispersa no cosmos; "branco" é a codificação derivada do espectro. "Quadrado branco" é a recodificação em termos da linguagem pictórica criada pelo suprematismo ${ }^{3}$ desenvolvido pelo artista para dar à arte um novo vocabulário pictórico.

O mesmo raciocínio pode ser dedicado à ciência. Quando a biologia concentrou em quatro letras a codificação para o complexo que é a informação genética, quatro unidades discretas recodificam a informação que, no organismo, é processada por outras representações que não são letras.

Com isso entende-se que a recodificação é o conhecimento já desenvolvido de outras semioses como a codificação biológica, fotoquímica, artística, a eletrônica, a digital etc. Nada indica que todos os códigos já foram esgotados nem ainda que as recodificações terminaram quando da passagem de uma dimensão a outra. Isso é só para dizer que os sistemas semióticos não operam com a informação (aquela definida como sinal de input e output na teoria da informação), mas com a informação codificada. Por conseguinte, as recodificações são as mediações que interessam às gestões semióticas do conhecimento. Remeto novamente a Jakobson (1971): as significações estão nos signos, não nas coisas.

Não será isso que afirmara McLuhan ao definir o meio como mensagem? Embora considerasse o meio e seus efeitos perceptivos no comportamento (dentro de um raciocínio raso de causalidade), McLuhan definiu o meio como informação codificada previamente, ou simplesmente como conteúdo, particularmente quando define a luz elétrica (informação) como meio (informação codificada) das mais diferentes "linguagens elétricas": rádio, televisão, cinema, que se expandiram em linguagens eletrônico-digitais, recodificando a informação. Talvez por isso sua proposição tenha causado tantos mal entendidos, o que nos obriga a investir nela esforços continuados de compreensão.

\section{Na história da mídia, tal como tem sido contada pelo encadeamento dos aparelhos eficientes, não há lugar para 0 signo nem para as mediações semióticas recodificadoras da informação.}

McLuhan escreveu um capítulo importante para história das mediações de um ponto de vista semiótico. Sua compreensão dos meios como tradutores se reporta à semiose centrada no processo de recodificação. Na verdade seu raciocínio se desdobra desde a concepção da eletricidade como meio, isto é, como informação que pode ser traduzida em códigos e dar origem a sistemas de signos. Também ao afirmar que, ao surgir, um novo meio recupera e recodifica a informação de outros, McLuhan oferece uma pista para se compreender a história transversalizada dos meios, colocando a "diacronia em pânico", tal como afirmara Haroldo de Campos em seus estudos sobre poética sincrônica. Também ao supervalorizar o "conteúdo" em sua formulação do "meio como mensagem", McLuhan procurou chamar a atenção para "natureza" dos códigos envolvidos no meio, ou seja, seu modo particular de recodificar a informação já codificada de alguma forma. Por isso ele afirmou radicalmente que o meio em si não significa nada, é mero veículo; só interessa mesmo enquanto conteúdo: "o 'conteúdo' de qualquer meio ou veículo é sempre um outro meio ou veículo. O conteúdo da escrita é a fala, assim como a palavra escrita é o conteúdo da imprensa e a palavra impressa é o conteúdo do telégrafo. Se alguém perguntar, 'Qual é o conteúdo da fala?', necessário se torna dizer: 'É um processo de pensamento, real, nãoverbal em si mesmo"” (McLuhan, 1972: 22).

Devemos também a McLuhan a noção segundo a qual a eletricidade inaugura uma outra história da cultura porque ela desencadeia um modo de perceber o mundo "tudo-ao-mesmo-tempo". Nesse cenário vivo de percep- 
ções em feixes, mais importante do que o veículo são as mediações que as recodificações realizam. Mediações que não se limitam às relações que se desenrolam no eixo da produção e da recepção, mas entre as próprias codificações. Este é o caminho que nos leva para os processos de realização de signos em sua semiose, ou, em suas mediações enquanto tecnologias cognitivas.

Perceber os códigos culturais em semiose num espaço de simultaneidades revela ordenamentos cognitivos que operam em conexão. Por exemplo, quando McLuhan analisa a linguagem do cinema como recodificação da fragmentação do cubismo, ele apresenta uma síntese pontual do que estamos a dizer. Ainda que escolha por tema uma narrativa, que implica uma dada continuidade, o sistema de signos cinematográficos organiza imagens, sons e movimentos a partir de signos que não são contínuos. E eis que o cinema desenvolve sob forma de linguagem um outro tipo de mediação sob forma de montagem. Não éà toa que a montagem continua desafiando o pensamento sobre a construção de uma linguagem resultante da mediação de processamento audiovisual acentuadamente intelectual. Somente pela montagem os signos discretos ganham uma projeção e um caráter de signos contínuos. Ao mundo da narrativa literária, que opera com signos discretos, se apõe o mundo dos signos não-discretos de caráter icônico. Não foi essa a grande novidade da fotografia com seus códigos de registro da luz que recodificou a informação luminosa em signo não-discreto disseminando a noção de uma civilização da imagem visual? As competências semióticas de ambos os sistemas são distintas, porém não excludentes. A informação que esta mídia nos oferece é um banquete de signos digno de servir o requinte do paladar de Homero. Se esse exemplo apresentado por McLuhan nos diz tanto sobre a importância da recodificação como processo semiótico e cognitivo que dizer, então, das chamadas linguagens híbridas onde a tensão semiótica se instala entre os próprios signos não-discretos?

Recodificação é um processo de mediação semiótica que não está localizada num meio específico, mas cada meio realiza de um modo e num grau particular. Para fazer valer as mediações como graduações de distintas semioses, entendemos que a palavra mídia (no singular) é insuficiente. Por conseguinte, na história da mídia, tal como tem sido contada pelo encadeamento dos aparelhos eficientes, não há lugar para o signo nem para as mediações semióticas recodificadoras da informação. Se existe um personagem na história das mediações semióticas este sem dúvida será uma entidade plural: os códigos. São eles que se transformam no tempo e nos espaços das interações.

Se a meta é compreender as recodificações que movimentam a comunicação mediada e a chamada cultura de mídias, a transmissão da informação não é um caminho favorável para se alcançar a história dos códigos e, conseqüentemente das linguagens da comunicação nos ambientes culturais. Nem mesmo o diagrama espacial da comunicação, também fundado no transporte, que serviu de ponto de partida e de fundamento teórico para os estudos das transmissões, pode dizer alguma coisa significativa sobre a performance da informação na cultura. Transporte também não dá conta de traduzir a complexidade dos sistemas de signos que emergem, seja da perspectiva da era da informação ou da emergente era da conexão. Os próprios historiadores e sociólogos da cultura apresentam argumentos que alimentam nosso pensamento ao mostrar que a era da conexão está marcada pela mobilidade difusa, pela convergência de mídias pervasivas, pela reciclagem e pelo hibridismo. Pena que a riqueza dessa observação tenha se homogeneizado em efeitos. Seria bem mais enriquecedor se as formulações se encaminhassem para se compreender as gestões semióticas onde a produção de signo é o pressuposto elementar da produção de conhecimento.

\section{Gestões semióticas do conhecimento}

Porque permite a mobilidade dos signos em processo de recodificação da informação (não de transporte), a cultura de meios, que se expandiu no eixo da cultura letrada, apresenta movimentos que são amplamente favoráveis para se pensar as gestões semióticas do conhecimento como fruto das mediações resultantes da informação codificada e recodificada.

Sem perder o diálogo com a história social da mídia a partir do qual estamos construindo nosso pensamento sobre mediações como semiose para alcançar uma outra história, é preciso distinguir nosso entendimento sobre as gestões semióticas do conhecimento que não pode ser confundido com "gestão social do conhecimento" de que trata, por exemplo, Pierre Lévy (1994). Ainda que esteja apoiado na mesma base epistemológica - a ecologia cognitiva de Gregory Bateson - aquilo que estamos denominando gestão semiótica não opera com a causalidade da descodificação da informação única com vistas à eficiência. Novamente invertemos a rota de formulações em curso. Se no centro da noção de gestão está a idéia de controle como um recurso com vistas ao desempenho maximizado de uma operação, tal como se entende o conceito de gestão nas organizações, no centro da noção de gestão semiótica está um dispositivo tradutório que se constitui como um "programa de ação", tal como Iúri Lótman entendeu a ação dos signos na constituição dos sistemas culturais. E isso é possível situar na expansão da escrita como sistema pervasivo e de leitura. Em vez de controle, o programa expressa apenas probabilidade, aliás, como toda operação tradutória ou de recodificação. A gestão semiótica chama a atenção para o modo de os diferentes sistemas se relacionarem nos espaços culturais e como eles significam dentro de um contexto de leitura. Nesse sentido, as máquinas semióticas se constituem objetos de nossa reflexão não porque elas são um meio (veículo), mas porque elas realizam conhecimentos traduzidos em forma de códigos. Por exemplo, não é o controle remoto instalado na chave de 
meu carro, que me dá conforto e segurança, o que interes$\mathrm{sa}$, mas a recodificação de conhecimentos que permitiram que um simples gesto de apertar o botão fosse recodificado tanto em forma de informação luminosa quanto de movimento de abertura de portas. Essas ações interligadas são lidas espacialmente uma vez me permite saber que o carro permanece no lugar estacionado e com as portas abertas. Entre meu dedo e o botão, entre este e a luz que pisca há uma cadeia de conhecimentos que são processadas semioticamente nesse ambiente de comunicação sensiente, como afirmara Lemos. Dela pouco sabemos e dela queremos nos aproximar porque nela está configurado todo um design da comunicação que éo termômetro da mente da cultura que envolve toda uma ecologia semiótica.

Se a cultura letrada estimulou a leitura como capacidade de reconhecer signos, a cultura de meios (ou de mídias) dá um passo adiante e reivindica algo além do reconhecimento: exige a capacidade de realizar intervenções. Não é isso que se exige de todos aqueles que se dispõem a operar os signos informáticos? Não basta reconhecer um programa é preciso saber como recodificar os códigos da informação digital para outras finalidades. Esse é um mundo de probabilidade fora de controle.

A idéia da gestão semiótica também tem sua história. Ela está vinculada às concepções de Iúri Lótman (1978) sobre as linguagens artificiais e secundárias que disputam em pé de igualdade o processo de interação e de troca de mensagens em contextos culturais em que o homem não é obrigatoriamente o agente central do processo comunicativo. Parte-se do pressuposto de que a linguagem natural pode ser modelizada por códigos culturais, onde se inserem também os códigos de máquina, laborados por conhecimentos científicos de largo espectro. Nesse sentido a gestão semiótica prescinde da mediação do código verbal e dinamiza conexões entre diversidades do espaço semiótico. Conexão com o radicalmente outro: outro código, outra linguagem, outros sistemas de signos. Isso me parece fundamental se quisermos entender adequadamente o que se insinua como "era da conexão" povoada por híbridos, emergências e movimentos migratórios de toda espécie. Em última análise, a proposta de compreensão das gestões semióticas do conhecimento é uma forma de compreender a relação dos códigos culturais no espaço a cultura sem se deixar levar pela sedutora estratégia de marketing que nos torna usuários, consumidores, proprietários de máquinas sofisticadas das quais não temos a mínima condição de adquirir os conhecimentos semióticos nelas envolvidos. Voltamos à condição do escriba que sabia copiar, mas não era dotado da possibilidade para ler os signos que escrevia, menos ainda de transformá-los.

Por isso, reivindicamos o lugar do signo na história, não da mídia, já que não é este seu lugar, mas das mediações. E este gesto significa trazer para o primeiro plano, não a causalidade, mas os processos de geração do conhecimento por meio de códigos culturais que, por sua vez, correspondem a classes diferenciadas de signos que tanto constituem as diferentes linguagens da comunicação quanto exigem, daqueles que com eles interagem, diferentes competências semióticas como, por exemplo, modelização de relações; leitura e escritura; codificação- descodificação-recodificação do conhecimento; tradução e transcriação científica. Embora distintas, tais competências estão interrelacionadas, colocando os signos em ação e interação, vale dizer, em semiose. Isso é o que entendemos por mediação das linguagens da comunicação.

O fato de não existir lugar para o signo na história da mídia acabou incitando nossa inquietação para situar seu lugar na história da cultura. Isso foi suficiente para alcançar a escrita como tecnologia do intelecto cultural; o surgimento da figura do homem leitor e tradutor de signos; e, particularmente, para entender o desenvolvimento de meios de comunicação como possibilidade de recodificar a informação dispersa no cosmos que a cultura não mede esforços para traduzir de modo inteligente mfamecos

\section{NOTAS}

* O presente artigo é uma reelaboração de conferência apresentada no I Congresso Internacional de História das Mídias. Centro Universitário de Comunicação e Arte, SENAC, São Paulo. De 26 a 30 de outubro de 2004.

1. Em “A luz e o cego", o fotógrafo Evgen Bavcar, portador de deficiência visual, examina o papel dos textos bíblicos que serviram de fonte para os artistas desenhar fisicamente os seres celestiais. "A importância do texto nos parece particularmente importante no caso de Moisés de Michelangelo. Os cornos de sua cabeça vêm de um erro de tradução no texto que serviu de suporte à figura. Que Michelangelo jamais viu Moisés, é evidente: foi o espaço do verbo que lhe forneceu a imagem mental em seguida trabalhada na pedra" (Bavcar, 1994: 461).

2. O reconhecimento das conseqüências da escrita referido aqui reporta-se aos argumentos formulados pelos antropólogos Jack Goody e Ian Watt (1968) para examinar as conseqüências do letramento na história da cultura.

3. Suprematismo designa a atividade pictórica de Maliévitch em termos de composição geométrica das formas. Embora muitos derivem a palavra do latim supremo, o que colocaria a forma suprema como o centro de sua atividade criativa e no conjunto da arte abstrata, a palavra é um neologismo criado pelo artista para definir a geometrização, mas isso não é suficiente para enquadrar o sua obra no campo da arte abstrata. 


\section{REFERÊNCIAS}

BAVCAR, Evgen (1994). A luz e o cego (trad. Rubens Machado). In Artepensamento (org. Adauto Novaes). São Paulo: Companhia das Letras.

BRIGGS, Asa \& BURKE, Peter (2004). Uma História Social da Mídia. De Gutenberg à Internet (trad. Maria C. P. Dias). Rio de Janeiro: Zahar.

CARPENTER, Edmund \& McLUHAN (1980). Revolução na comunicação (trad. Álvaro Cabral). Rio de Janeiro: Zahar.

CASTELLS, Manuel (1999). A sociedade em rede. A era da informação: economia, sociedade e cultura. Rio de Janeiro: Zahar.

COULMAS, Florian (1989). The writing systems of the world. Cambridge, Blackwell.

GOODY, Jack \& WATT, Ian (1968). The consequences of Literacy. In Perspectives on Literacy (Eugene R. Kintgen e outros (orgs.). Carbondale and Edwardsville: Southern Illinois University Press, 1988.

JACOMY, Bruno (2002). A era do controle remoto. Crônicas da inovação tecnológica (trad. Lucy Magalhães). Rio de Janeiro: Zahar.

JAKOBSON, Roman (1971). Lingüística e comunicação (trad. Izidoro Blikstein e José Paulo Paes). São Paulo: Cultrix.

LEMOS, André (org.) (2004a). Cibercidade. As cidades na cibercultura. Rio de Janeiro: E-Papers.

(2005). Cibercidade II. Ciberurbe. A cidade na sociedade da Informação. Rio de Janeiro: E-Papers.

(2004b). Cibercultura e mobilidade: a era da conexão. Razón y Palabra, n. 41, Octubre/ Noviembre, México (www.cem.itesm.mx/dacs/ publicaciones/logos/actual (acessado em 19/ 10/2004).

(2007a). Cidade Digital. Salvador: EDUFBa.

(2007b). Mídias locativas e territórios informacionais. In Estéticas tecnológicas, Lucia Santaella \& Priscila Arantes (orgs.). São Paulo: Educ.

LÉVY, Pierre (1993). As tecnologias da inteligência. O futuro do pensamento na era da informática (trad. Carlos Irineu da Costa). Rio de Janeiro: 34.
Ensaios de Semiótica Soviética (trad. Salvato T.

Meneses). Lisboa: Novo Horizonte.

LOTMAN, I. (1978). A estrutura do texto artístico (trad. M.C.V.Raposo). Lisboa: Estampa.

(1990). The Universe of the Mind. A Semiotic Theory of Culture (trad. Ann Shukmann). Bloomington: Indiana University Press.

McLUHAN, Marshall (1971). Os meios de comunicação como extensões do homem (trad. Décio Pignatari). São Paulo: Cultrix.

MARVIN, Carolyn (1988). When Old Technologies Were New. Thinking About Eletric Communication in the Late Neneteenth Century. Oxford: Oxford University Press.

SONESSON, Göran (1997). The Multimediation of the Lifeworld. Semiotics of the Media: state of the art, projects, and perspectives (Winfried Noth, ed.). Berlin-New York: Mouton de Gruyter.

VAZ, Paulo (2002). História das tecnologias cognitivas. Revista Fronteiras. Estudos Midiáticos, vol. IV, n. 2, pp. 101-120, dez. 2002.

WEINBERGER, D. (2003). Why Open Spectrum Matters. The end of the Broadcast Nation. http:/ / www.evident.com (acessado em 19/10/2004).

WINSTON, Brian (1998). Media Technology and Society. A History: from the Telegraph to the Internet. London and New York: Routledge.

LOTMAN, I.; USPENSKII, B.; IVANOV, V. (1981). 